\title{
Efluentes cloacales y el derecho del agua
}

Elena I.Sogari $(*)$

\section{RESUMEN}

En el presente trabajo se aborda el derecho al agua, mencionando las normas internacionales y nacionales, analizando no solo el dominio, sino también su aprovechamiento y tutela del agua. Para ello se presenta el análisis de un fallo que fue resuelto por la Justicia provincial, referido al derecho del agua, y las consecuencias de los efluentes cloacales vertidos en él.

La medida adoptada por la empresa fue de arrojar los líquidos cloacales directamente a las aguas del Río Paraná y sin ningún tratamiento previo y de modo indiscriminada, siendo el motivo por el cual, la acción fue tratada y resuelta en sede judicial, a fin de hacer cesar la contaminación de las aguas del Río Paraná y el deterioro de la calidad de la vida las personas, muchas de ellas de escasos recursos, priorizando el derecho a la salud de las personas y el derecho al medio ambiente, que son derechos de rango constitucional. Nuestra Constitución Nacional garantiza el principio de publicidad de los actos de gobierno y el derecho de acceso a la información pública.

El mecanismo de acceso a dicha información promueve el respeto de los principios de igualdad, publicidad, celeridad, informalidad y gratuidad.

\section{INTRODUCCIÓN}

En el presente trabajo se aborda del derecho al agua, mencionando las normas internacionales y nacionales, analizando no solo el dominio, sino también su aprovechamiento y tutela.

Es por eso que se analiza, un fallo que fue resuelto por la Justicia provincial, que se vincula con el derecho del agua, como consecuencias de los efluentes cloacales. Estas actitudes que son realizadas por el accionar del hombre, implicando de modo inmediata la apropiación del bien, con la particular característica de que los costos 
por el uso de esos bienes, lo asumimos todos. Todas las personas, tenemos derecho a solicitar, acceder y recibir información, no siendo necesario que se demuestre tener un interés legítimo o particular, no que le patrocine un profesional letrado (abogado, escribano). Como lo hizo el Sr. Merlo Apolinario al demandar a la empresa Aguas de Corrientes S.A, a fin de que la empresa demandada informe "acerca del tratamiento y destino de los desagües cloacales" que realiza en 13 ciudades de la provincia, entre ellas la capital.

El "dominio" de las aguas implica reconocer la riqueza hídrica como punto de partida del aprovechamiento de agua en ciudades, en el campo, en la industria y en general en el progreso de regiones, pueblos y naciones (CAMPO, 2010). El artículo 235 Del Código Civil y Comercial de la Nación enumera los bienes que quedan afectados al régimen de dominio público: "los ríos, estuarios, arroyos y demás aguas que corren por cauces naturales, los lagos y lagunas navegables, los glaciares y el ambiente periglacial y toda otra agua que tenga $o$ adquiera la aptitud de satisfacer usos de interés general, comprendiéndose las aguas subterráneas, (...)".

Las mayorías de las legislaciones modernas ya no plantean la categorización del agua en públicas o privadas, sino que la regulan en función del ciclo hidrológico y del valor estratégico económico, social y ambiental del recurso hídrico, respetando y protegiendo sus usos y aprovechamiento del agua.
Su disponibilidad en condiciones de calidad y cantidad es un condicionante para el desarrollo que, como "sustentable" es incorporado como objetivo mediante el art. 41 en la Constitución Nacional (CN).

\section{MATERIALES Y MÉTODOS}

Este trabajo se origina del análisis del fallo judicial realizado en la provincia de Corrientes, a cargos de los jueces María Eugenia Sierra de Desimoni, Carlos Anibal Rodriguez, integrantes de la Sala IV de la Cámara de Apelaciones en lo civil y Comercial de Corrientes, en autos caratulados "Merlo Apolinario c/Aguas de Corrientes S.A, Administración de Obras Sanitarias de Corrientes y Estado de provincia de Corrientes s/media autosatisfactiva (conocimiento), ordenaron a la empresa demandada que informe " acerca del tratamiento y destino de los desagües cloacales" que realiza en 13 ciudades de la provincia, entre ellas la capital.

Los magistrados, revocaron la sentencia de primera instancia e hicieron lugar a una medida autosatisfactiva, donde se denunció la descarga de efluentes cloacales sin tratamiento previo con la consecuente contaminación de las aguas y el deterioro de la calidad de vida de las personas, muchas de ellas de escasos recursos.

\section{RESULTADOS}

La acción fue promovida contra la empresa Aguas de Corrientes S.A, el Ente 
Regulador de la Administración de Obras Sanitarias de la Provincia de Corrientes (A.O.S.C.) y contra el Estado provincial para que en seis meses apliquen un plan integral de saneamiento ambiental que incluya, entre otras medidas, la construcción de plantas de tratamiento sanitario de efluentes de aguas cloacales en todas las ciudades donde se brinde el servicio.

La Cámara dispuso que el juez de primera instancia fije el plazo por el cual la empresa deberá informar "acerca del tratamiento y destino de los desagües cloacales de las ciudades de Corrientes, Saladas, Be1la Vista, Curuzú Cuatiá, Monte Caseros, Mercedes, Santo Tomé, Esquina, Goya, Santa Lucía, Yapeyú, Empedrado, Paso de los Libres y cualquier otra localidad donde la empresa Aguas de Corrientes S.A. tenga concesionado el servicio, debiendo detallar el número de terminales cloacales, contenido y volumen de líquidos arrojados". Es un deber jurídico, por parte de las empresas prestatarias de servicio público, informar a sus usuarios, de todas las medidas adoptadas con el fin de no afectar el medio ambiente.

\section{DISCUSIÓN}

Para el autor Marienhoff, las aguas son públicas por "afectación" o "destino", correspondiendo establecer qué circunstancias o caracteres deben tenerse en cuenta para "afectar" las aguas al dominio público". Continúa expresando que para incluirlas en dicha categoría se debe considerar la importancia que tenga el agua para la región, factor que se encuentra determinado por la utilidad.

El agua no escapa a los caracteres generales de los bienes, que es un objeto material apropiable actual o virtualmente (SPOTA). Pero es importante resaltar que las aguas de cualquier especie no son susceptibles de apropiación exclusiva y que por ende se deben por necesidad económica pertenecer al Estado, y como bien debe ser tutelado por el Estado.

En el ámbito internacional el derecho humano al agua es reconocido en varios acuerdos o pactos e instrumentos jurídicos, como la Convención sobre Eliminación de toda forma de Discriminación contra las Mujeres, que señala "Los Estados Partes aseguren a las mujeres el derecho a gozar de condiciones de vida adecuadas particularmente en las esferas de (...) el abastecimiento de agua" y la Convención sobre los Derechos del Niño, que exige a los Estados Partes que luchen contra las enfermedades y la malnutrición mediante " el suministro de alimentos adecuados y agua potable salubre".

Las Naciones Unidas, hace varios años que está abordando la crisis mundial como consecuencia de un abastecimiento de agua insuficiente y dado la creciente demanda de agua para satisfacer las necesidades humanas, comerciales y agrícolas.

En el Derecho interno, la Argentina ha ratificado la Convención de los dere- 
chos Humanos y contemplados en nuestra Constitución Nacional con la reforma del 1994, otorgándole jerarquía constitucional.

En nuestra Carta Magna, trata de los recursos naturales y el ambiente. En el capítulo Segundo de nuestra Constitución Nacional, se regulan los nuevos derechos y garantías constitucionales, en el Art.43 segundo párrafo de la Constitución $\mathrm{Nacional}^{1}$ y el art. 41 de la Constitución Nacional2.

Para el desarrollo del ser humano, el agua y los sistemas de saneamiento no pueden estar separados. Ambos son fundamentales para reducir la carga mundial de enfermedades y para mejorar la salud, la educación y la productividad económica de la población del Nordeste. E1 art. 124 de la Constitución Nacional al expresar que "corresponde a las provincias el dominio originario de los recursos naturales existentes en su territorio". El aprovechamiento híbrido corresponde a la jurisdicción provincial, manifestando que la competencia de los magistrados provinciales, en resolver el planteo formulado por el actor, conforme lo faculta el art. 121 de la Constitución Nacional al establecer que: "dado que las provincias se han reservado todos los derechos que no han delegado expresamente en la nación"

\footnotetext{
${ }^{1}$ Artículo 43- Toda persona puede interponer acción expedita y rápida de amparo, siempre que no exista otro medio judicial más idóneo, contra todo acto u omisión de autoridades públicas o de particulares, que en forma actual o inminente lesione, restrinja, altere o amenace, con arbitrariedad o ilegalidad manifiesta, derechos y garantías reconocidos por esta Constitución, un tratado o una ley. En el caso, el juez podrá declarar la inconstitucionalidad de la norma en que se funde el acto u omisión lesiva. Podrán interponer esta acción contra cualquier forma de discriminación y en lo relativo a los derechos que protegen al ambiente, a la competencia, al usuario y al consumidor, así como a los derechos de incidencia colectiva en general, el afectado, el defensor del pueblo y las asociaciones que propendan a esos fines, registradas conforme a la ley, la que determinará los requisitos y formas de su organización.

Toda persona podrá interponer esta acción para tomar conocimiento de los datos a ella referidos y de su finalidad, que consten en registros o bancos de datos públicos, o los privados destinados a proveer informes, y en caso de falsedad o discriminación, para exigir la supresión, rectificación, confidencialidad o actualización de aquellos. No podrá afectarse el secreto de las fuentes de información periodística.

Cuando el derecho lesionado, restringido, alterado o amenazado fuera la libertad física, o en caso de agravamiento ilegítimo en la forma o condiciones de detención, o en el de desaparición forzada de personas, la acción de habeas corpus podrá ser interpuesta por el afectado o por cualquiera en su favor y el juez resolverá de inmediato aun durante la vigencia del estado de sitio

${ }^{2}$ Artículo 41- Todos los habitantes gozan del derecho a un ambiente sano, equilibrado, apto para el desarrollo humano y para que las actividades productivas satisfagan las necesidades presentes sin comprometer las de las generaciones futuras; y tienen el deber de preservarlo. E1 daño ambiental generará prioritariamente la obligación de recomponer, según lo establezca la ley. Las autoridades proveerán a la protección de este derecho, a la utilización racional de los recursos naturales, a la preservación del patrimonio natural y cultural y de la diversidad biológica, y a la información y educación ambientales.

Corresponde a la Nación dictar las normas que contengan los presupuestos mínimos de protección, y a las provincias, las necesarias para complementarlas, sin que aquellas alteren las jurisdicciones locales. Se prohíbe el ingreso al territorio nacional de residuos actual o potencialmente peligrosos, y de los radiactivos.
} 
En la Provincia de Corrientes, existe un Código de Aguas, en su art. 6. Que Define los siguientes términos a) aprovechamiento $\mathrm{y} \mathrm{b}$ ) contaminar. Respecto al primero establece que "es el conjunto de proyectos y obras que el Estado y/o los particulares definan o instrumenten para disponer, dentro del marco de la Politica Hidrica, el justo, óptimo y eficiente uso, goce, conservación y preservación de los recursos hidricos". El segundo expresa "Dicese de la acción de verter o agregar en los cursos de aguas, lagunas, embalses, materiales, sustancias, gases, ondas, temperatura y/o energias residuales o inmisiones de cualquier indole que por su presencia o actividad pudieran provocar, directa o indirectamente, alteraciones en la condición normal del recurso, traducidas en consecuencias sanitarias, económicas, estéticas, recreacionales, ecológicas, negativas indeseables. Además se incluye toda acción que, sin llegar a bacerla peligrosa para la salud humana, tornare las aguas no aptas para el uso que con ellas se realice, perniciosas para el medio ambiente o la vida que se desarrolla en los cursos de agua o aquellas que por generar olor, sabor, temperatura, color o peculiaridades físico-quimicas resultaren o causaren molestias o daños comprobables".

Las definiciones supra mencionadas expresan que las aguas son uno de los factores más trascendentes que rompen la armo- nía entre el hombre y su medio, no sólo de forma inmediata sino, también a mediano y largo plazo.

El agua es una necesidad humana necesaria para la vida de las personas y esencial para vivir con dignidad que debe ser acatado por la sociedad y el Estado.

La Ley 25.675, Ley General del Ambiente ${ }^{3}$, determina los presupuestos mínimos para lograr de una gestión sustentable y adecuada del ambiente, la preservación y protección de la diversidad biológica y a la vez la implementación del desarrollo sustentable.

El Estado se ve obligado adoptar y aplicar medidas y acciones en cumplimiento delos objetivos de políticas contentando en la misma ${ }^{4}$. En el apartado a) establece que si afirmamos que las personas humanas, posee la capacidad de cambiar el medio que lo rodea, este atributo en ejercicio, conforme a la realización de distintas actividades antrópicas, incluyendo las actividades del estado deberán asegurar la preservación, la conservación, recuperación de los recursos ambientales. En el apartado b) al mencionar calidad de vida, la doctrina define como "La percepción del individuo de su situación de vida, como del contexto de su cultura y el sistema de valores en que vive, y en relación a sus objetivos, expectativas, estándares y preocupaciones

${ }^{3}$ Ley 25.675. Sancionada: 06/11/02. Promulgada y Publicada B.O 28/11/02 
(ESCOBAR, 2000). Para la Organización Mundial de la Salud, calidad de vida la define: "El estado de complemento y bienestar físico, mental y social de una persona, y no sólo la ausencia de síntomas o de una afección determinada".

La degradación del Rio Paraná por culpa exclusiva y excluyente en el accionar positivo de la empresa demandada y en la omisión del control por parte del ente regulador, el proceso culminó con el fallo de marras, acreditando fehacientemente la contaminación ambiental, violando las normas nacionales e internacionales como de la organización Mundial de la Salud.

La ley N 25.688. Régimen de Gestión Ambiental de Agua establece los presupuestos mínimos de protección ambiental para la preservación de las aguas, su aprovechamiento y uso racional, en el marco de lo establecido en el art. 41 de nuestra Constitución Nacional.
En la Constitución Provincial de Corrientes, en el Capítulo $\mathrm{X}$ denominada "Del Ambiente. En el artículo 49: Toda persona tiene el derecho a gozar de un ambiente sano y equilibrado y el deber de preservarlo para las generaciones presentes y futuras. La calidad de vida, es uno de los parámetros de condiciones mínimas que debe tener presente el medio físico, tanto para las generaciones presentes como futuras.

Siguiendo con el análisis del mismo Capítulo de la Constitución Provincial, reza el Artículo 52: Toda persona puede interponer la acción prevista en el artículo 67 de esta Constitución, en protección del ambiente o con el objeto de hacer cesar las actividades que en forma actual o inminente causen o puedan causar daño ambiental, entendido como cualquier modificación o alteración negativa relevante al equilibrio del ecosistema, los recursos, los bienes o valores colectivos.

\footnotetext{
${ }^{4}$ El art 2 de dicha ley expresa:" a) Asegurar la preservación, conservación, recuperación y mejoramiento de la calidad de los recursos ambientales, tanto naturales como culturales, en la realización de las diferentes actividades antrópicas; b) Promover el mejoramiento de la calidad de vida de las generaciones presentes y futuras, en forma prioritaria; c) Fomentar la participación social en los procesos de toma de decisión; d) Promover el uso racional y sustentable de los recursos naturales; e) Mantener el equilibrio y dinámica de los sistemas ecológicos; f) Asegurar la conservación de la diversidad biológica; g) Prevenir los efectos nocivos o peligrosos que las actividades antrópicas generan sobre el ambiente para posibilitar la sustentabilidad ecológica, económica y social del desarrollo; h) Promover cambios en los valores y conductas sociales que posibiliten el desarrollo sustentable, a través de una educación ambiental, tanto en el sistema formal como en el no formal; i) Organizar e integrar la información ambiental y asegurar el libre acceso de la población a la misma; j) Establecer un sistema federal de coordinación interjurisdiccional, para la implementación de políticas ambientales de escala nacional y regional k) Establecer procedimientos y mecanismos adecuados para la minimización de riesgos ambientales, para la prevención y mitigación de emergencias ambientales y para la recomposición de los daños causados por la contaminación ambiental”. ${ }^{5}$ Ley N 25.688 Régimen de Gestión Ambiental de Aguas. Sancionada: 28/11/02. Publicada: 30/01/03.
} 
Quien promueva la acción está eximido del pago de tasas judiciales. Las pericias, estudios, trámites o pruebas requeridas en el proceso para demostrar la afectación o daño producido serán solventados por el Estado, salvo que las costas fueran impuestas al demandado y conforme lo determine la ley.

Tanto nuestra Constitución provincial, como las nuevas constituciones provinciales, contienen disposiciones que tutelan el ambiente, los recursos naturales, el patrimonio histórico y cultural, otorgándoles medios de acción para efectivizar su protección.

\section{CONCLUSIONES}

Conforme a nuestra Constitución $\mathrm{Na}-$ cional, las Autoridades se encuentran obligadas a proveer información ambiental a los habitantes. La publicidad de los actos de gobierno, como expresa el art. 41 de la Constitución Nacional, constituye una de las piedras angulares del Estado de Derecho. En caso de no brindar información a la persona que lo solicita en este caso analizado, antes la concesionaria Aguas de $\mathrm{Co}-$ rrientes S.A.

Administración de Obras Sanitarias de Corrientes y Estado de provincia de Corrientes, no cabe otra alternativa que recurrir ante la justicia, dado que nuestra Cons- titución nacional y provincial considera que vivimos en una democracia participativa, significando que cualquier ciudadano puede solicitar información ambiental y el aseguramiento del libre acceso de la población a la solicitud. La Ley $25.831^{6}$. Para lograr una participación eficaz, la misma debe ser informadas, siendo de gran interés que el mecanismo sea lo más sencillo y expedito posible, que al extenderle el informe sea sintetizada de manera clara y de fácil comprensión.

Todos los ciudadanos estamos legitimados en solicitar información pública ambiental en la protección del ambiente. Al resultar factible que los líquidos cloacales son volcado directamente a las aguas del Río Paraná y sin ningún tratamiento previo y de modo indiscriminada, fue el motivo por el cual, la acción fue tratada y resulta en sede judicial, a fin de hacer cesar la contaminación de las agua y el deterioro de la calidad de vida de las personas, muchas de ellas de escasos recursos, priorizando el derecho a la salud de las personas y al medio ambiente.

El agua es, una cuestión de derechos y a medida que crece la población mundial, resulta necesario conciliar la competencia entre las demandas comerciales de los recursos hídricos para que las comunidades tengan lo suficiente para satisfacer sus necesidades.

${ }^{3}$ Ley 25.831 de información Pública Ambiental. Sancionada: 26/11/03 y Publicada: 07/01/04 


\section{BIBLIOGRAFÍA}

La Conferencia de las Naciones Unidas sobre el La Constitución Nacional. Agua. Año 1977

La Constitución Provincial de Corrientes.

El Decenio internacional del Agua Potable y del Saneamiento Ambiental. 1981-1990.

Código de Aguas de la Provincia de Corrientes.

La Conferencia internacional sobre el agua y el La Ley 25.675, Ley General del Ambiente. medio ambiente 1992.

La Cumbre para la Tierra- 1992.

La ley N 25.688. Régimen de Gestión Ambiental de Aguas.

E1 Decenio Internacional de Acción “Agua para Ley 25.831 de información Pública Ambiental. la Vida"2005- 2015. 